\title{
Use of a care bundle in the emergency department for acute exacerbations of chronic obstructive pulmonary disease: a feasibility study
}

This article was published in the following Dove Press journal:

International Journal of COPD

28 November 2013

Number of times this article has been viewed

\author{
Cormac McCarthy' \\ John R Brennan' \\ Lindsay Brown' \\ Deirdre Donaghy' \\ Patricia Jones' \\ Rory Whelan ${ }^{2}$ \\ Niamh McCormack ${ }^{3}$ \\ Ian Callanan ${ }^{4}$ \\ John Ryan ${ }^{2}$ \\ Timothy J McDonnell1,3 \\ 'Department of Respiratory Medicine, \\ St Vincent's University Hospital, \\ Dublin, Ireland; '2Department of \\ Emergency Medicine, St Vincent's \\ University Hospital, Dublin, Ireland; \\ ${ }^{3}$ Clinical Strategy and Programmes \\ Directorate, Health Service Executive, \\ Dublin, Ireland; ${ }^{4}$ Department of Audit, \\ St Vincent's University Hospital, \\ Dublin, Ireland
}

Correspondence: Cormac McCarthy Education and Research Centre, Royal College of Surgeons in Ireland, Beaumont Hospital, Dublin 9, Ireland

Tel +353 I8093796

Email cmccarthy@rcsi.ie
Aim: To determine the efficacy and usefulness of a chronic obstructive pulmonary disease (COPD) care bundle designed for the initial management of acute exacerbations of COPD and to assess whether it improves quality of care and provides better outcomes.

Introduction: The level of care provided in the emergency department (ED) for COPD exacerbations varies greatly, and there is a need for a more systematic, consistent, evidence-based quality improvement approach to improve outcomes and costs.

Methods: A prospective before and after study was carried out in a university teaching hospital. Fifty consecutive patients were identified in the ED with COPD exacerbations and their management was reviewed. Following the education of ED staff and the implementation of a COPD care bundle, the outcome for 51 consecutive patients was analyzed. This COPD care bundle consisted of ten elements considered essential to the management of COPD exacerbations and was scored 0-10 according to the number of items on the checklist implemented correctly.

Results: Following implementation, the mean bundle score out of 10 improved from 4.6 to $7(P<0.001)$. There was a significant decrease in the unnecessary use of intravenous corticosteroids from $60 \%$ to $32 \%(P=0.003)$ and also a marked improvement in the use of oxygen therapy, with appropriate treatment increasing from $76 \%$ to $96 \%(P=0.003)$. Prophylaxis for venous thromboembolism also improved from $54 \%$ to $73 \%(P=0.054)$. The 30 -day readmission rate did not significantly improve.

Conclusion: The use of a bundle improves the delivery of care for COPD exacerbations in the ED. There is more appropriate use of therapeutic interventions, especially oxygen therapy and intravenous corticosteroids.

Keywords: COPD, checklist, bundle, exacerbations, steroids

\section{Introduction}

Acute exacerbations of chronic obstructive pulmonary disease (COPD) account for a considerable number of acute medical admissions, with the majority being admitted through the emergency department (ED). There were 10,863 admissions in Ireland for COPD in 2010 , which account for $2.3 \%$ of all hospital inpatients, excluding maternity services, and COPD exacerbations were the most common single reason for hospital admission. ${ }^{1}$ The mean length of stay was 9.5 days, creating a considerable burden on health services. There is a high mortality rate associated with exacerbations of COPD, and many patients are readmitted within 90 days of discharge. ${ }^{2-4}$ Many studies have commented on the varying levels of care and outcomes of these admissions and highlighted the need for more systematic, consistent, evidence-based quality improvement approaches to improving outcomes from COPD exacerbations. ${ }^{5,6}$ In an analysis of almost 
70,000 admissions with exacerbations of COPD in the United States, Lindenauer et $\mathrm{al}^{6}$ noted that only $66 \%$ of patients received the entire set of recommended care processes. A similar study from Canada showed deficits in the administration of bronchodilators, steroids, antibiotics, and oxygen in the care of patients hospitalized with acute exacerbations of COPD. ${ }^{7}$ Inappropriate high-flow oxygen administration prior to hospital admission may give rise to hypercapnia, respiratory acidosis, and increased mortality compared with titrated oxygen in patients with exacerbations of COPD. ${ }^{8}$

With the increasing complexity of management and pressure on time in delivering acute medical care, critical components of appropriate care may be overlooked. One approach to the issue of ensuring adequate delivery of goodquality, safe health care has been the utilization of checklists or bundles of care. These provide in pro forma form a series of key steps that should not be overlooked in the assessment and management of a clinical condition. They have been demonstrated in surgery and in the management of indwelling catheters to improve safety. ${ }^{9,10}$ Recently, Robb et $\mathrm{al}^{11}$ have used a series of bundles for a number of medical conditions to improve overall hospital mortality.

This study aimed to develop and implement a COPD admission bundle for use in the ED and assess whether it improved overall care in the acute setting. A COPD bundle was developed based on best international evidence and practice. The care and outcome of patients with COPD exacerbations before and after the implementation of the bundle were measured.

\section{Methods}

\section{Study design and patient demographics}

The study was carried out in the ED of a university teaching hospital in Dublin, Ireland. Inclusion criteria were any patient admitted through the ED with a diagnosis of COPD and evidence of an acute exacerbation with no other acute medical issue at the time of presentation. A diagnosis of COPD was made on the available clinical information, including general practitioner referral letters, spirometry, if available, and clinical assessment. An exacerbation was defined on clinical assessment by the ED physician as the presence of at least one of the following: increased dyspnea, increased sputum volume, or increased sputum purulence.

The study consisted of two separate periods. The initial phase involved a 3-month period to analyze all COPD admissions during this time and retrospectively review the management in the ED and the eventual outcomes. The second phase of the study consisted of a prospective analysis of the management and outcomes in patients with COPD following the implementation of a care bundle designed for patients with COPD exacerbations. This was a pilot feasibility study, as no power calculation was performed; instead, an arbitrary 3-month period was used to assess the use of a care bundle preimplementation and postimplementation.

The design of the COPD bundle consisted of selecting items based on national and international guidelines, a systematic literature review, and input from a multidisciplinary project team. ${ }^{12,13}$ The goal of the bundle was to be accurate, inclusive, and simple to follow. The COPD bundle from Robb et $\mathrm{al}^{11}$ was modified to incorporate ten elements that should all be implemented within 24 hours of admission. Items were selected for the bundle based on their importance in the management of COPD exacerbations but particularly if they were perceived as being poorly implemented in usual care. Examples of poorly implemented components of acute COPD care were noted from the literature and input from the multidisciplinary team. The clinical advisory group to the COPD program of the Clinical Strategy and Programmes Directorate of the Health Service Executive, Dublin, Ireland, was also canvassed for input.

The ten elements selected for inclusion in the bundle were:

1. Correct administration of supplemental oxygen

2. Checking an arterial blood gas

3. Administration of bronchodilators

4. Reviewing laboratory results

5. Obtaining a chest radiograph

6. Administration of oral antibiotics if no evidence of pneumonia

7. Administration of oral corticosteroids

8. Consideration for COPD outreach program

9. Referral to respiratory service

10. Commencement of venous thromboembolism prophylaxis.

The elements of the bundles were made available to clinicians in a printed bundle, which was attached to the ED notes (see Figure 1).

This study involved the closure of an audit loop. One of the authors was chairman of the local audit committee and was involved with development of the study from the outset. Ethical approval was consequently not required. The Standards for Quality Improvement Reporting Excellence (SQUIRE) ${ }^{14}$ guidelines were utilized in the framing of this report.

The COPD outreach program is a service designed to provide a safe, planned, early discharge home from hospital or the ED for patients with an acute exacerbation of COPD. Suitable patients (approximately $20 \%-25 \%$ of patients) are 


\begin{tabular}{|c|c|c|}
\hline \multicolumn{3}{|c|}{ Patient presents to ED/AMU/MAU } \\
\hline \multicolumn{3}{|c|}{$\begin{array}{l}\text { Patient assessed by EM/AMU/MAU clinician and appropriate investigations ordered } \\
\text { CXR, ECG, ABGs, blood tests } \\
\text { FBC, U+E, LFTS, CRP (if available) }\end{array}$} \\
\hline Action & $\begin{array}{l}\text { Time completed or } \\
\text { reason for variation }\end{array}$ & Signed \\
\hline 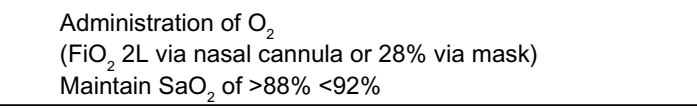 & On presentation & \\
\hline $\begin{array}{l}\text { Check arterial blood gas and repeat if } \mathrm{FiO}_{2} \text { increase is } \\
\text { required or hypercapnia. If in respiratory failure with } \\
\mathrm{pH}<7.35 \text { consider initiation of non-invasive ventilation/ } \\
\text { transfer to appropriate unit }\end{array}$ & $\begin{array}{l}\text { Within } 30 \text { minutes of } \\
\text { presentation }\end{array}$ & \\
\hline $\begin{array}{l}\text { Administer nebulised Beta } 2 \text { agonists and/or } \\
\text { anticholinergics }\end{array}$ & $\begin{array}{l}\text { Within } 30 \text { minutes of } \\
\text { presentation }\end{array}$ & \\
\hline Oral prednisone $40 \mathrm{mg}$ ( $30 \mathrm{mg}$ if $60 \mathrm{~kg}$ or less) & $\begin{array}{l}\text { Within } 2 \text { hours of } \\
\text { presentation }\end{array}$ & \\
\hline Review laboratory results & $\begin{array}{l}\text { Within } 2 \text { hours of } \\
\text { presentation }\end{array}$ & \\
\hline Review chest X-ray & $\begin{array}{l}\text { Within } 2 \text { hours of } \\
\text { presentation }\end{array}$ & \\
\hline $\begin{array}{l}\text { Administer antibiotics po amoxicillin or clarithromycin or } \\
\text { doxycycline } \\
\text { If new infiltrate treat as pneumonia (see pneumonia } \\
\text { bundle) }\end{array}$ & $\begin{array}{l}\text { Within } 4 \text { hours of } \\
\text { presentation }\end{array}$ & \\
\hline $\begin{array}{l}\text { Consider COPD outreach (complete inclusion/exclusion } \\
\text { criteria) }\end{array}$ & $\begin{array}{l}\text { Within } 4 \text { hours of } \\
\text { presentation }\end{array}$ & \\
\hline Ted stockings or LMWH for prophylaxis (if admitted) & $\begin{array}{l}\text { Within } 8 \text { hours of } \\
\text { admission }\end{array}$ & \\
\hline $\begin{array}{l}\text { Refer to respiratory team/nurse } \\
\text { If patient is currently smoking or an ex-smoker }<3 \text { months } \\
\text { refer to smoking cessation service } \\
\text { If appropriate refer to AHP (physio, OT, dietetics, SW, etc) }\end{array}$ & $\begin{array}{l}\text { Within } 24 \text { hours of } \\
\text { admission }\end{array}$ & \\
\hline
\end{tabular}

Figure I COPD bundle.

Note: COPD Outreach supported early discharge: Certain patients will continue to be assessed for suitability for early discharge within 72 hours of presenting to the ED/ AMAU by COPD Outreach team. Patients who fulfil the criteria, have a diagnosis of COPD and give their CONSENT will be recruited for early supported discharge.

Abbreviations: AMAU, acute medical assessment unit; ABGs, arterial blood gases; AHP, allied health professional; AMU, acute medical unit; COPD, chronic obstructive pulmonary disease; CXR, chest X-ray; ECG, electrocardiogram; ED, emergency department; EM, emergency medicine; FiO ${ }_{2}$, fraction of inspired oxygen; LMWH, lowmolecular-weight heparin; MAU, medical assessment unit; $\mathrm{O}_{2}$, oxygen; OT, occupational therapist; $\mathrm{SaO}_{2}$, saturation level of oxygen in hemoglobin; SW, social worker; LFTs, liver function tests; CRP, C-reactive protein; FBC, full blood count; U+E, urea and electrolytes.

discharged and visited at home by members of the outreach team over the following days until stable. Inclusion and exclusion criteria are outlined in Table 2. This service is designed to reduce length of stay and also provides a support service for COPD patients through the provision of pulmonary rehabilitation and education.

\section{Phase I of study: initial assessment of COPD care in the ED}

Fifty consecutive patients with an exacerbation of COPD during the initial period from October to December 2010 were reviewed in the ED following admission. Patients were assessed as having an exacerbation of COPD by the ED staff.
An alternative diagnosis made in the ED excluded patients who, for example, presented with congestive cardiac failure or pneumonia. A small number of patients may have had an alternative diagnosis made later in their hospitalization. The patients had been assessed and a management plan decided by the admitting medical team when they were reviewed. Demographic data were collected, including age, sex, and forced expiratory volume in 1 second $\left(\mathrm{FEV}_{1}\right)$. The triage notes, ED physician notes, and medication records were reviewed for evidence of comorbidities of COPD. Documentation in the notes of a comorbidity or record of prescribed medication for one was accepted as evidence supporting the presence of comorbidity. Specifically, records 
were evaluated for hypertension, ischemic heart disease, congestive cardiac failure, diabetes, osteoporosis, depression, and lung cancer. The smoking status documented in the notes was recorded. A retrospective analysis was carried out on the number of elements involved in the COPD bundle that were correctly followed. Assessment of compliance was made by a specialist respiratory nurse. Subsequently, the length of stay was noted along with the rate of readmission within 30 days and the number of deaths.

\section{Phase 2 of study: assessment of COPD care and outcomes following implementation of the COPD care bundle}

To ensure that the COPD bundle would be effectively implemented, an education session for all staff in the ED was held to communicate the reasons for implementing it. This was conducted by a respiratory physician and the respiratory clinical nurse specialists and highlighted evidence of deficits in care of COPD exacerbation in the literature and local experience and the resultant rationale for the components of the COPD bundle. The management of COPD and the rationale for the bundle were also presented and discussed at medical grand rounds. Following this the COPD care bundle was implemented in the ED. Fifty-one consecutive patients with an exacerbation of COPD during the 3-month period from March to May 2011 were suitable for inclusion. Again, all relevant patient demographics were gathered and analyzed in an identical manner to phase 1. Analysis of the implementation of all elements of the bundle was carried out.
Similarly, the outcome measures, including length of stay and 30-day readmission rate, were assessed.

\section{Statistical analysis}

The differences in both appropriate management and outcomes before and after implementation of the COPD bundle were analyzed using Microsoft Excel (Microsoft Corporation, Redmond, WA, USA) and SPSS (version 17.0.1, IBM Corporation, Armonk, NY, USA). Data were nonparametric in distribution, and the Mann-Whitney $U$ test and $\chi^{2}$ tests were performed. $P$-values and $95 \%$ confidence intervals were calculated. A $P$-value of $<0.05$ was considered as representing statistical significance.

\section{Results}

There were 50 patients in the preimplementation group and 51 patients in the postimplementation group. The mean age was similar in the two groups at 70 years (range 42-90 years) and 72 years (46-89 years). The sex distribution was similar in both groups: $52 \%$ males in the preimplementation group and 59\% in the postimplementation group (see Table 1).

There was a slight difference in the mean $\mathrm{FEV}_{1}$ between the two groups; however, this was not statistically significant. The preimplementation group had a mean $\mathrm{FEV}_{1}$ of $1.23 \mathrm{~L}$ (53\% predicted) and the postimplementation group had a mean $\mathrm{FEV}_{1}$ of $1.01 \mathrm{~L}$ (43\% predicted). There was no significant difference noted in the comorbidities between both groups, and many of the patients had multiple comorbidities (see Table 3).

Table I Demographics of patients pre- and post bundle implementation

\begin{tabular}{|c|c|c|c|}
\hline & Preimplementation & Postimplementation & $P$-value \\
\hline No of patients & 50 & 51 & \\
\hline Male/female (\%) & $26 / 24(52 / 48)$ & $30 / 21(59 / 4 I)$ & $P=0.49$ \\
\hline Age (range) (years) & $70(42-90)$ & $72(46-89)$ & $P=0.43$ \\
\hline Mean LOS & 11.8 & 9 & $P=0.3779$ \\
\hline Median LOS & 6 & 7 & \\
\hline Range & $0-123$ & $0-60$ & \\
\hline No of readmissions in 30 days & $6(12 \%)$ & $7(14 \%)$ & $P=0.75$ \\
\hline Mean care bundle score $(0-10)$ & $4.6(I-7)$ & $7(3-10)$ & $P<0.0001$ \\
\hline No of patients given correct $\mathrm{FiO}_{2}$ & $38(76 \%)$ & 49 (96\%) & $P=0.0032$ \\
\hline No of patients given intravenous steroids & $30(60 \%)$ & $16(32 \%)$ & $P=0.0035$ \\
\hline No of patients given intravenous antibiotics & $16(32 \%)$ & $17(33 \%)$ & $P=0.72$ \\
\hline No of patients given VTE prophylaxis & $27(54 \%)$ & $37(73 \%)$ & $P=0.054$ \\
\hline Mean FEV, L (Range) & I. $23 \mathrm{~L}(0.53-2.72)$ & I.0I L (0.43-2.03) & $P=0.086$ \\
\hline Mean FEV, \% (Range) & $53 \%(19-124)$ & $43 \%(15-90)$ & \\
\hline Mean $\mathrm{FEV}_{\text {, }}$ of patients readmitted in 30 days & I.27 L (60\%) & $0.68 \mathrm{~L}(32.4 \%)$ & $P=0.046$ \\
\hline No of deaths & 0 & 1 & $P=0.32$ \\
\hline
\end{tabular}

Abbreviations: $\mathrm{FEV}_{1}$, forced expiratory volume in I second; $\mathrm{FiO}_{2}$, fraction of inspired oxygen; LOS, length of stay; VTE, venous thromboembolism. 
Table 2 Inclusion and exclusion criteria for chronic obstructive pulmonary disease (COPD) outreach program

\begin{tabular}{|c|c|}
\hline Inclusion & Exclusion \\
\hline $\mathrm{FEV}_{1}<80 \%$ predicted & Suspected malignancy \\
\hline $\mathrm{FEV}_{1} / \mathrm{FVC}<70 \%$ predicted & $\begin{array}{l}\text { Pneumothorax, } \\
\text { pneumonia }\end{array}$ \\
\hline Abbreviated mental test score $>7$ & Uncontrolled LVF \\
\hline Systolic blood pressure $>100 \mathrm{mmHg}$ & Acute ECG changes \\
\hline $\begin{array}{l}\text { ABGs pH }>7.35, \mathrm{PO}_{2}>7.3 \mathrm{kPa} \\
\mathrm{PCO}_{2}<8 \mathrm{kPa} \text { (on room air) }\end{array}$ & Requires full-time care \\
\hline Total WCC 4-20 × 10/I & Insufficient home care \\
\hline 0-72 hrs of presenting to hospital & Requires IV therapy \\
\hline Contact details: $x x x x x$ & Type I diabetes \\
\hline Or page $x x x / x x x / x x x$ & \\
\hline
\end{tabular}

Abbreviations: $A B G$ s, arterial blood gases; $E C G$, electrocardiogram; $\mathrm{FEV}_{\text {, }}$, forced expiratory volume in I second; FVC, forced vital capacity; IV, intravenous; LVF, left ventricular function; $\mathrm{PCO}_{2}$, pressure of carbon dioxide in the blood; $\mathrm{PO}_{2}$, pressure of oxygen in the blood; WCC, white cell count.

The improvement in appropriate management of COPD exacerbations was evident following implementation of the bundle use. Of the ten elements essential to the initial assessment and management of each exacerbation, initially the mean number of elements addressed was 4.6 (range one to seven). However, following the use of the care bundle, this improved to seven (range three to ten), which was statistically significant $(P<0.001)$ (Table 1).

There was a significant improvement in the appropriate early performance of arterial blood gases from $36 \%$ to $98 \%$ of patients $(P<0.001)$ but no change in the documentation of laboratory or chest $\mathrm{X}$-ray results. With regard to the delivery of appropriate therapy, there was significant improvement with more appropriate prescription of the fraction of inspired oxygen given to each patient. This increased from $76 \%$ of patients to $96 \%$ receiving the correct oxygen concentration $(P=0.003)$. Similarly, the number of patients given intravenous steroids decreased considerably from $60 \%$ of patients

Table 3 Comorbidities in pre- and post bundle cohorts

\begin{tabular}{llll}
\hline & $\begin{array}{l}\text { Prebundle } \\
\text { (\%) }\end{array}$ & $\begin{array}{l}\text { Postbundle } \\
\text { (\%) }\end{array}$ & $\begin{array}{l}\text { Total } \\
\text { (\%) }\end{array}$ \\
\hline Ischemic heart disease & 28 & 39.2 & 33.7 \\
Hypertension & 30 & 45.1 & 37.6 \\
Congestive heart failure & 26 & 5.9 & 15.8 \\
Hypercholesterolemia & 32 & 45.1 & 38.6 \\
Diabetes mellitus & 6 & 13.7 & 9.9 \\
Osteoporosis & 22 & 31.4 & 26.7 \\
Depression & 26 & 27.5 & 26.7 \\
Lung cancer & 0 & 5.9 & 2 \\
Smoking status & & & \\
$\quad$ Ex-smokers & 48 & 58.8 & 53.5 \\
$\quad$ Current smokers & 40 & 27.5 & 33.7 \\
$\quad$ Never smokers & 2 & 5.9 & 4 \\
$\quad$ Unknown & 10 & 7.8 & 8.9 \\
\hline
\end{tabular}

to $32 \%$ postimplementation $(P=0.003)$. However, there was no significant change in the number of patients receiving intravenous antibiotics, the proportion of patients being $32 \%$ preimplementation and $33 \%$ postimplementation $(P=0.72)$.

The rate of patients receiving appropriate venous thromboembolism prophylaxis also improved from $54 \%$ to $73 \%$. This was not statistically significant but approached significance $(P=0.054)$.

There was no significant change in the 30-day readmission rate: $12 \%$ prior to the bundle implementation versus $14 \%$ postimplementation $(P=0.75)$. There was no statistically significant difference in the median length of stay: 6 days (range 0-123 days) preimplementation as opposed to 7 days (range 0-60 days) following the bundle implementation $(P=0.3779)$.

\section{Discussion}

This study provides further evidence supporting a role for the use of bundles in certain aspects of health care delivery. The results demonstrate that the use of a care bundle to assess and manage patients with acute exacerbations of COPD in the ED is associated with an improvement in the delivery of care. The use of a bundle is simple, easy to follow, and decreases inappropriate management decisions.

The education of emergency staff is vital to improving COPD management, and the use of a bundle augments this type of management. ${ }^{5}$ The bundle used in this study has ten simple steps and was easy to follow. This study has demonstrated that of the ten elements in the bundle, the average number of elements that were correctly implemented significantly increased from 4.6 to seven. This is a significant increase; however, there is still room for improvement, and ideally all ten elements of the care bundle should always be implemented. Seemingly mundane and simple tasks are often overlooked in the emergency setting, and the use of a bundle helps reduce oversights such as these. Something as simple as referral to a respiratory service within 24 hours should improve care and appropriateness of treatment and allows more efficient long-term follow-up.

An improvement in the 30-day readmission rate and length of stay in hospital in the COPD study population was anticipated. There was no statistically significant improvement in either the readmission rate or length of stay following implementation of the bundle. This may relate to the numbers studied or to the difference in lung function and comorbidities between the two groups. Most likely the relatively small number of patients in both periods contributed to the observed lack of improvement in length of stay 
following implementation of the bundle. The second group tended to have a lower average $\mathrm{FEV}_{1}$ in both liters and percent predicted. The preimplementation group had a better $\mathrm{FEV}_{1}$ of $1.27 \mathrm{~L}\left(60 \%\right.$ predicted) compared with an $\mathrm{FEV}_{1}$ of $0.68 \mathrm{~L}(32 \%$ predicted) in the postimplementation group. This may help explain the equivalent readmission rates in the two groups, as although overall care was improved in the second group, they may have been a more severe cohort and had a higher likelihood of experiencing another exacerbation in a short period of time.

The decreased use of intravenous corticosteroids is important, as it decreases the potential side effects from intravenous use compared with the safer oral route of administration. Hyperglycemia in COPD exacerbations has been associated with poor outcomes, ${ }^{15}$ and previous studies have demonstrated that use of oral corticosteroids is not inferior to intravenous treatment. ${ }^{6,16}$ In the current environment, where cost is so fundamental to appropriate delivery of care, the increased expenditure from unnecessary treatments is unacceptable. Improving the cost-effectiveness of treatment of COPD exacerbations is vital to further enhance COPD services overall. ${ }^{6,17,18}$

Although we demonstrated an improvement in quality of care of patients with COPD exacerbations following the introduction of a COPD bundle, it is difficult to be certain that the bundle alone was responsible for this. Any improvement could have been related to the general increased awareness of the need to improve the care of COPD following the demonstration of indices of poor-quality care. It would not have been possible or ethical to do a randomized study in the same institution, and having a prestudy and a poststudy does raise the possibility of other factors producing the observed improvement in care. Although this study was carried out in a single center, we believe that with local adaptation this type of COPD bundle could be used widely, as the acute presentation of COPD exacerbations is similar worldwide. This study supports the hypothesis that correct management of acute exacerbations of COPD can be improved with the use of a care bundle, and the results should be widely applicable, as the fundamental elements of management are universal.

\section{Conclusion}

This study demonstrates that a simple bundle can improve care of COPD exacerbations. This can help rectify commonly missed elements of care and augment best evidence-based treatments. The use of this bundle not only streamlines care but also has the potential to reduce the risk of adverse effects from unnecessary medications or treatments. Implementing a care bundle could possibly lead to a decrease in the length of stay and reduce readmission rates, but this will require further study. Furthermore, as shown in this study, the use of a bundle can alter prescribing practices and subsequently may have implications in improving costs through reduction of unnecessary medications. Education of all staff involved in the assessment and treatment of COPD exacerbations is essential to further improve COPD care.

\section{Disclosure}

The authors report no conflicts of interest in this work.

\section{References}

1. The Economic and Social Research Institute. Activity in Acute Public Hospitals in Ireland, 2010 Annual Report. Dublin, Ireland: The Economic and Social Research Institute. Available from: http://www. esri.ie/health_information/latest_hipe_nprs_reports/2010_hipe_report/. Accessed October 3, 2013.

2. Roberts CM, Barnes S, Lowe D, Pearson MG. Evidence for a link between mortality in acute COPD and hospital type and resources. Thorax. 2003;58(11):947-949.

3. Price LC, Lowe D, Hosker HS, Anstey K, Pearson MG, Roberts CM. UK National COPD Audit 2003: impact of hospital resources and organisation of care on patient outcome following admission for acute COPD exacerbation. Thorax. 2006;61(10):837-842.

4. Roberts CM, Lowe D, Bucknall CE, Ryland I, Kelly Y, Pearson MG. Clinical audit indicators of outcome following admission to hospital with acute exacerbation of chronic obstructive pulmonary disease. Thorax. 2002;57(2):137-141.

5. Sen B, Woollard M, Desira NL. Does the introduction of a COPD proforma improve the standards of care delivered by junior doctors in the emergency department. COPD. 2010;7(3):199-203.

6. Lindenauer PK, Pekow P, Gao S, Crawford AS, Gutierrez B, Benjamin EM. Quality of care for patients hospitalized for acute exacerbations of chronic obstructive pulmonary disease. Ann Intern Med. 2006;144(12):894-903.

7. FitzGerald JM, Haddon JM, Bradly-Kennedy C, Kuramoto L, Ford GT; RUSIC Study Group. Resource use study in COPD (RUSIC): a prospective study to quantify the effects of COPD exacerbations on health care resource use among COPD patients. Can Respir J. 2007;14(3): $145-152$.

8. Austin MA, Wills KE, Blizzard L, Walters EH, Wood-Baker R. Effect of high flow oxygen on mortality in chronic obstructive pulmonary disease patients in prehospital setting: randomised controlled trial. BMJ. 2010;341:c546.

9. Berwick DM, Calkins DR, McCannon CJ, Hackbarth AD. The 100,000 lives campaign: setting a goal and a deadline for improving health care quality. JAMA. 2006;295(3):324-327.

10. Pronovost $\mathrm{P}$, Needham $\mathrm{D}$, Berenholtz $\mathrm{S}$, et al. An intervention to decrease catheter-related bloodstream infections in the ICU. $N$ Engl $J$ Med. 2006;355(26):2725-2732.

11. Robb E, Jarman B, Suntharalingam G, Higgens C, Tennant R, Elcock K. Using care bundles to reduce in-hospital mortality: quantitative survey. BMJ. 2010;340:c1234.

12. Rabe KF, Hurd S, Anzueto A, et al. Global strategy for the diagnosis, management, and prevention of chronic obstructive pulmonary disease: GOLD executive summary. Am J Respir Crit Care Med. 2007;176: 532-555.

13. Celli BR, MacNee W. Standards for the diagnosis and treatment of patients with COPD: a summary of the ATS/ERS position paper. Eur Respir J. 2004;23(6):932-946. 
14. Ogrinc G, Mooney SE, Estrada C et al. The SQUIRE (Standards for QUality Improvement Reporting Excellence) guidelines for quality improvement reporting: explanation and elaboration. Qual Saf Health Care. 2008 Oct;17 Suppl 1:i13-32. PMID: 18836062.

15. Baker EH, Janaway CH, Philips BJ, et al. Hyperglycaemia is associated with poor outcomes in patients admitted to hospital with acute exacerbations of chronic obstructive pulmonary disease. Thorax. 2006;61(4): 284-289.

16. de Jong YP, Uil SM, Grotjohan HP, Postma DS, Kerstjens HA, van den Berg JW. Oral or IV prednisolone in the treatment of COPD exacerbations: a randomized, controlled, double-blind study. Chest. 2007;132(6):1741-1747.
17. Patil SP, Krishnan JA, Lechtzin N, Diette GB. In-hospital mortality following acute exacerbations of chronic obstructive pulmonary disease. Arch Intern Med. 2003;163(10):1180-1186.

18. Daniels JM, Snijders D, de Graaff CS, Vlaspolder F, Jansen HM, Boersma WG. Antibiotics in addition to systemic corticosteroids for acute exacerbations of chronic obstructive pulmonary disease. Am J Respir Crit Care Med. 2010;181(2):150-157.

International Journal of COPD

\section{Publish your work in this journal}

The International Journal of COPD is an international, peer-reviewed journal of therapeutics and pharmacology focusing on concise rapid reporting of clinical studies and reviews in COPD. Special focus is given to the pathophysiological processes underlying the disease, intervention programs, patient focused education, and self management protocols.

\section{Dovepress}

This journal is indexed on PubMed Central, MedLine and CAS. The manuscript management system is completely online and includes a very quick and fair peer-review system, which is all easy to use. Visit http://www.dovepress.com/testimonials.php to read real quotes from published authors.

Submit your manuscript here: http://www.dovepress.com/international-journal-of-copd-journal 